\title{
Comparison of Short-term Results after Laparoscopic Complete Mesocolic Excision and Standard Colectomy for Right-Sided Colon Cancer: Analysis of a Western Center Cohort
}

\author{
Cristian Conti ${ }^{1}$, Corrado Pedrazzani ${ }^{1}$, Giulia Turri ${ }^{1}$, Eduardo Fernandes ${ }^{2}$, Enrico Lazzarini ${ }^{1}$, \\ Raffaele De Luca ${ }^{3}$, Alessandro Valdegamberi ${ }^{1}$, Andrea Ruzzenente ${ }^{1}$, Alfredo Guglielmi ${ }^{1}$ \\ ${ }^{1}$ Division of General and Hepatobiliary Surgery, Department of Surgical Sciences, Dentistry, Gynecology, and Pediatrics, University of Verona \\ Hospital Trust, University of Verona, Italy; ${ }^{2}$ Division of Minimally Invasive, General and Robotic Surgery, University of Illinois at Chicago, \\ Chicago, IL, USA; ${ }^{3}$ Department of Surgical Oncology, IRCCS-ISTITUTO TUMORI “G. Paolo II”, Bari, Italy
}

Purpose: Laparoscopic complete mesocolic excision (CME) right colectomy is a technically demanding procedure infrequently employed in Western centers. This retrospective cohort study aims to analyze the safety of laparoscopic CME colectomy compared to standard colectomy for right-sided colon cancer in a Western series.

Methods: Prospectively collected data from 60 patients who underwent laparoscopic CME right colectomy were compared to the ones of 55 patients who underwent laparoscopic standard right colectomy.

Results: No differences in clinical characteristics were observed between the CME and standard right colectomy groups. No differences were demonstrated in terms of blood loss $(\mathrm{P}=0.060)$, intraoperative complications $(\mathrm{P}=1)$, conversion rate $(\mathrm{P}=0.102)$, and operative time $(\mathrm{P}=0.473)$. No deaths were observed in either group, while complication rate was $40.0 \%$ in the $\mathrm{CME}$ and $49.1 \%$ in the standard group $(\mathrm{P}=0.353)$. Severe complications occurred in $10.0 \%$ vs. $9.1 \%(\mathrm{P}=0.842)$, redo surgery in $5.0 \%$ vs. $7.3 \%(\mathrm{P}=0.708)$, and unplanned readmission in $5.0 \%$ vs. $5.5 \%(\mathrm{P}=1)$ after $\mathrm{CME}$ and standard colectomy, respectively. A significant difference in favor of CME was observed in the total length of specimen $(\mathrm{P}<0.001)$, proximal $(\mathrm{P}=0.018)$, and distal margins $(\mathrm{P}=0.037)$. The number of lymph nodes harvested was significantly higher in the CME group (27 vs. 22, $\mathrm{P}=0.037$ ).

Conclusion: In Western series, where patients have less favorable clinical characteristics, laparoscopic CME allows to obtain better quality surgical specimens and comparable short-term outcomes compared to standard right colectomy.

Keywords: Laparoscopy; Right hemicolectomy; Colonic neoplasms; Complete mesocolic excision

\section{INTRODUCTION}

Surgical resection represents the mainstay of treatment for colorec-

Received: Mar 11, 2020 - Revised: May 17, 2020 • Accepted: May 18, 2020 Correspondence to: Corrado Pedrazzani, M.D.

Division of General and Hepatobiliary Surgery, University Hospital

"G.B. Rossi", Piazzale L. Scuro 10, 37134 Verona, Italy

Tel: +39-45-8126719, Fax: +39-45-8027426

E-mail: corrado.pedrazzani@univr.it

ORCID: https://orcid.org/0000-0003-2431-6117

(C) 2021 The Korean Society of Coloproctology

This is an open-access article distributed under the terms of the Creative Commons Attribution NonCommercial License (https://creativecommons.org/licenses/by-nc/4.0) which permits unrestricted non-

commercial use, distribution, and reproduction in any medium, provided the original work is properly cited. tal cancer (CRC). The quality of surgery is one of the key factors determining long-term outcomes. Laparoscopic surgery is considered the gold standard for CRC, having comparable long-term and better short-term outcomes compared to open surgery $[1,2]$.

Complete mesocolic excision (CME) with central vascular ligation (CVL), as Hohenberger et al. [3] proposed in open surgery, have gained interest also in the laparoscopic and robotic setting [4-6]. The key feature of CME with CVL is the dissection of the colon along embryological planes and the division of the supplying arteries at their origin. This allows harvesting lymph node along the entire length of the main vessels. The technique provides a better specimen quality, an improved control of circumferential resection margins, and a complete removal of the lymphatic 
basins. The result is a wide bowel resection with an en bloc and complete resection of the mesocolon and draining lymph nodes $[3,7-9]$.

Another major advantage of this technique is that it helps in defining clearly the surgical anatomy and anatomical surgical planes and structures $[7,10]$. This is particularly true in right colon cancer (CC) surgery where vascular anatomical variations are frequent especially when approaching the middle colic vessels area [11-13].

D3 lymphadenectomy, as proposed by Eastern authors, resembles CME with CVL concept and it is routinely performed in many centers in Japan, Korea, and China. Conversely, only few series of laparoscopic CME with CVL/D3 lymphadenectomy have been published by Western authors [4].

The aim of the present study was to analyze the safety and feasibility of laparoscopic CME right colectomy and to compare its short-term results with standard right colectomy in a single Western center.

\section{METHODS}

This is a single-center, prospectively collected, and retrospectively analyzed observational study. Data were analyzed from 60 patients who underwent laparoscopic CME with D3 lymphadenectomy for right-sided CC at the Division of General and Hepatobiliary Surgery, University of Verona Hospital Trust between September 2014 and March 2019. The control group included 55 patients who underwent a standard laparoscopic right hemicolectomy between April 2013 and March 2019. The study was approved by the Institutional Review Board and Ethics Committee of the University of Verona Hospital (No. 42763-CRINF-1034 CESC). Informed consent was obtained from all patients enrolled in the study.

The CME procedure was previously described in detail in a multimedia article with a video demonstration of our technique [14]. D3 lymphadenectomy entailed the en bloc resection of lymph nodes along the superior mesenteric vessels taking the left border of the superior mesenteric vein as landmark of the outer boundary of the lymphadenectomy. Lymph node dissection was performed after lateral-to-medial and caudal-to-cranial colon mobilization. For tumors involving the cecum, the ascending colon, and the hepatic flexure, the lymphadenectomy included dissection of the origin of the middle colic artery and vein and the division of the right branch of the middle colic vessels. The left branch of middle colic vessels was preserved and was taken as reference for the division of the mesocolon (Fig. 1A, 1B). For transverse colon tumors, the middle colic vessels were divided at their origin (Fig. 1C). Starting from September 2014, all cases of tumors staged equal or higher than T2 or node-positive at preoperative computed tomography scan and operated on by a surgeon (CP) underwent a CME right colectomy (Fig. 1D).

Standard right colectomy was carried out by CP and 2 other sur-
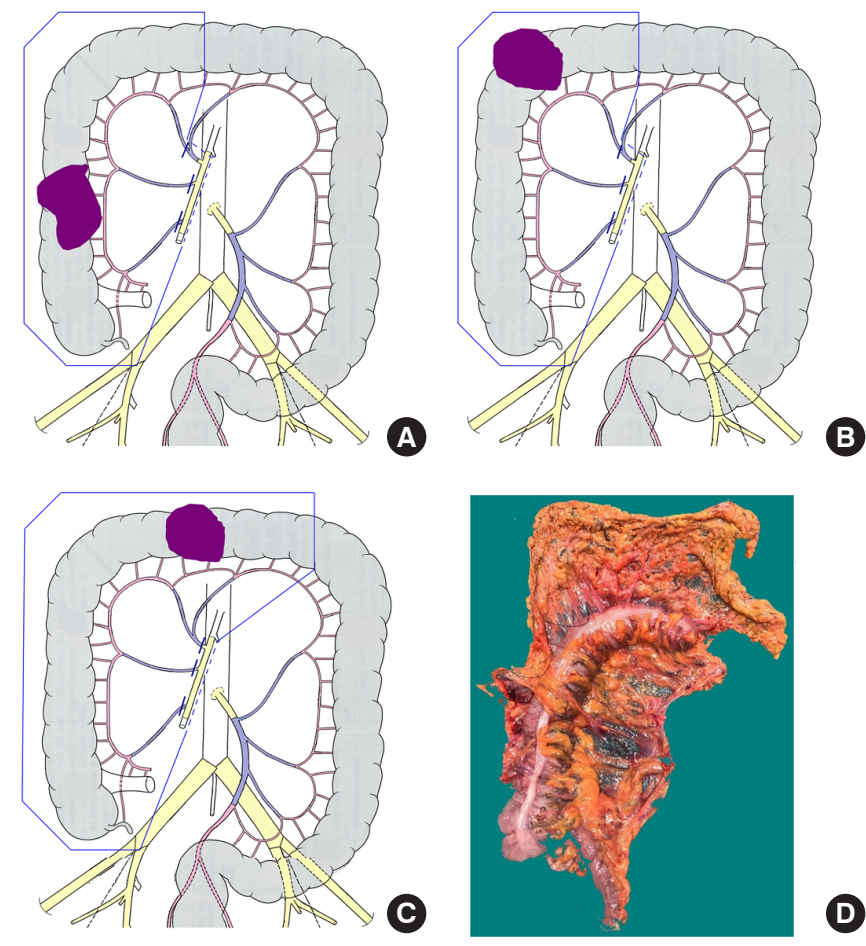

Fig. 1. Schematic representation of the extent of colonic resection and lymph node dissection for tumor of the cecum/ascending colon (A), hepatic flexure (B) and transverse colon (C), and example of surgical specimen demonstrating the full resection and integrity of the mesocolon (D).

geons with experience of more than 50 laparoscopic colorectal resections using either a lateral-to-medial or medial-to-lateral approach with the division of the vessels at their origin. The main difference between CME and standard colectomy was that, in the latter, the lymphadenectomy was not carried out beyond the right border of superior mesenteric vein (D2 lymphadenectomy according to the guidelines of Japanese Society for Cancer of the Colon and Rectum).

Pathology specimens were analyzed according to the 7th edition of the American Joint Committee on Cancer and the Union for International Cancer Control criteria. Tumor size, length of specimens, and surgical resection margins were obtained from formalin-fixed specimens.

\section{Data collection and statistical analysis}

Postoperatively, patients were evaluated by a member of the surgical team at least twice a day. Any deviation from the normal postoperative course was considered a complication. Postoperative morbidity and mortality accounted for all adverse events occurring in-hospital or within 30 days after surgery. Complications were graded according to the Clavien-Dindo classification [15].

All demographics, clinical and outcome data were prospectively collected and stored in a dataset of personal computer. Continu- 
ous data were analyzed with the Student t-test or the KruskalWallis test as appropriate. Categorical data were compared using the chi-square test or Fisher exact test. Continuous data were presented as means \pm standard deviations, or medians (ranges). Categorical data were presented as frequencies. A P-value of $<0.05$ was considered statistically significant. Statistical analysis was performed using IBM SPSS Statistics software ver. 21.0 (IBM Corp., Armonk, NY, USA).

\section{RESULTS}

Patients' demographics, clinical characteristics, and operative data

Table 1. Demographic and clinical characteristics according to treatment group

\begin{tabular}{|c|c|c|c|}
\hline Characteristic & $\begin{array}{c}\text { Standard right } \\
\text { hemicolectomy }\end{array}$ & $\begin{array}{c}\text { CME right } \\
\text { hemicolectomy }\end{array}$ & P-value \\
\hline Patient & $55(100)$ & $60(100)$ & \\
\hline Age (yr) & $69.6 \pm 10.2$ & $71 \pm 11.1$ & 0.469 \\
\hline Sex & & & 0.853 \\
\hline Male & $27(49.1)$ & $31(51.7)$ & \\
\hline Female & $28(50.9)$ & $29(48.3)$ & \\
\hline Indication for surgery & & & 0.023 \\
\hline Adenoma & $5(9.1)$ & $0(0)$ & \\
\hline Adenocarcinoma & $50(90.9)$ & $60(100)$ & \\
\hline Tumor location & & & 0.716 \\
\hline Cecum & $21(38.2)$ & $17(28.8)$ & \\
\hline Ascending & $19(34.5)$ & $24(40.0)$ & \\
\hline Hepatic flexure & $11(20.0)$ & $13(21.7)$ & \\
\hline Transverse & $4(7.3)$ & $6(10.0)$ & \\
\hline Body mass index $\left(\mathrm{kg} / \mathrm{m}^{2}\right)$ & $25.5 \pm 4.8$ & $26.6 \pm 5$ & 0.204 \\
\hline ASA PS classification & & & 0.766 \\
\hline I & $2(3.6)$ & $2(3.3)$ & \\
\hline$\|$ & $35(63.6)$ & $40(66.7)$ & \\
\hline III & $17(30.9)$ & $18(30.0)$ & \\
\hline IV & $1(1.8)$ & $0(0)$ & \\
\hline Presence of comorbidities & & & 0.559 \\
\hline None & $14(25.5)$ & $13(21.7)$ & \\
\hline 1 & $19(34.5)$ & $17(28.3)$ & \\
\hline$\geq 2$ & $22(40.0)$ & $30(50.0)$ & \\
\hline Previous abdominal surgery & & & 0.879 \\
\hline None & $30(54.5)$ & $35(58.3)$ & \\
\hline 1 & 17 (30.9) & $16(26.7)$ & \\
\hline$\geq 2$ & $8(14.5)$ & $9(15.0)$ & \\
\hline
\end{tabular}

Values are presented as number (\%) or mean \pm standard deviation.

CME, complete mesocolic excision; ASA, American Society of Anesthesiologists; PS, physical status. are reported in Tables 1 and 2. No significant differences were noted between the standard and the CME colectomy groups. Mean age was around 70 years in both groups, more than $40 \%$ of patients presented 2 or more comorbidities, and about $30 \%$ were classified as American Society of Anesthesiologists (ASA) physical status (PS) classification III. A body mass index (BMI) greater than $28 \mathrm{~kg} / \mathrm{m}^{2}$ was observed in $25.5 \%$ of standard colectomies and in $31.7 \%$ of CME colectomies ( $\mathrm{P}=0.538)$. Obesity (BMI $>30$ $\mathrm{kg} / \mathrm{m}^{2}$ ) was recorded in $10.9 \%$ of standard colectomies and $16.7 \%$ in CME colectomies $(\mathrm{P}=0.428)$.

All CME procedures were performed by the same surgeon $(\mathrm{CP})$, who also performed 32 standard colectomies $(58.2 \%)$. The percentage of right colectomies extended to transverse colon was comparable between $\mathrm{CME}$ and standard groups $(\mathrm{P}=0.156)$. No differences were observed between the 2 groups in terms of blood loss $(\mathrm{P}=0.060)$, occurrence of intraoperative complications $(\mathrm{P}=1)$, conversion rate $(\mathrm{P}=0.102)$, and operative time $(\mathrm{P}=0.473)$. The $\mathrm{CME}$ group had a smaller size mini-laparotomy performed $(\mathrm{P}=$ 0.01 ) likely due to the higher number of intracorporeal anastomosis ( $33.3 \%$ vs. $18.2 \%, \mathrm{P}=0.089$ ).

The results of histopathological examinations are reported in Table 3. In the standard group, 16 patients (29.1\%) underwent surgery for an adenoma not amenable to endoscopic resection. Patients in the CME group had a higher rate of advanced (pT3

Table 2. Surgical procedure data by treatment group

\begin{tabular}{|c|c|c|c|}
\hline Variable & $\begin{array}{l}\text { Standard right } \\
\text { hemicolectomy } \\
(n=55)\end{array}$ & $\begin{array}{l}\text { CME right } \\
\text { hemicolectomy } \\
(n=60)\end{array}$ & P-value \\
\hline Extent of colonic resection & & & 0.156 \\
\hline Right hemicolectomy & $48(87.3)$ & $46(76.7)$ & \\
\hline Extended right hemicolectomy & $7(12.7)$ & $14(23.3)$ & \\
\hline Associated surgical procedure & $12(21.8)$ & $14(23.3)$ & 1 \\
\hline Type of anastomosis & & & 0.089 \\
\hline Extracorporeal & $45(81.8)$ & $40(66.7)$ & \\
\hline Intracorporeal & $10(18.2)$ & $20(33.3)$ & \\
\hline Site of incision & & & 0.719 \\
\hline Periumbilical & $42(84.0)$ & $52(88.1)$ & \\
\hline Suprapubic & $6(12.0)$ & $6(10.2)$ & \\
\hline Other & $2(4.0)$ & $1(1.7)$ & \\
\hline Length of incision (cm) & $6.5 \pm 2.0$ & $5.4 \pm 1.2$ & 0.010 \\
\hline Duration of anesthesia (min) & $252 \pm 63$ & $265 \pm 65$ & 0.286 \\
\hline Duration of surgery (min) & $209 \pm 56$ & $217 \pm 58$ & 0.473 \\
\hline Blood loss (mL) & $75 \pm 63$ & $54 \pm 48$ & 0.060 \\
\hline Intraoperative complication & $2(3.6)$ & $3(5.0)$ & 1 \\
\hline Conversion & $5(9.1)$ & $1(1.7)$ & 0.102 \\
\hline
\end{tabular}

Values are presented as number (\%) or mean \pm standard deviation.

CME, complete mesocolic excision. 
and pT4) tumors compared to the standard colectomy group (70\% vs. $29.1 \%$; $\mathrm{P}<0.001$ ).

The length of specimen was significantly higher in the CME

Table 3. Histopathological data by treatment group

\begin{tabular}{|c|c|c|c|}
\hline Variable & $\begin{array}{l}\text { Standard right } \\
\text { hemicolectomy } \\
\quad(n=55)\end{array}$ & $\begin{array}{l}\text { CME right hemi- } \\
\text { colectomy } \\
(n=60)\end{array}$ & P-value \\
\hline Specimen length (cm) & $27.3 \pm 9.5$ & $33.3 \pm 8.1$ & 0.001 \\
\hline Proximal margin length $(\mathrm{cm})$ & $12.1 \pm 7.1$ & $15.8 \pm 9.2$ & 0.018 \\
\hline Distal margin length $(\mathrm{cm})$ & $11.3 \pm 6.8$ & $14.0 \pm 6.7$ & 0.037 \\
\hline Tumor size (cm) & $3.0 \pm 2.0$ & $2.7 \pm 2.1$ & 0.539 \\
\hline Depth of tumor invasion & & & $<0.001$ \\
\hline Dysplasia, pTis & $16(29.1)$ & $0(0)$ & \\
\hline pT1 & $9(16.4)$ & $5(8.3)$ & \\
\hline pT2 & $14(25.5)$ & $13(21.7)$ & \\
\hline pT3 & $10(18.2)$ & $30(50.0)$ & \\
\hline рT4a & $4(7.3)$ & $9(15.0)$ & \\
\hline pT4b & $2(3.6)$ & $3(5.0)$ & \\
\hline Number of nodes analyzed & $21.7 \pm 2.9$ & $27.0 \pm 11.3$ & 0.007 \\
\hline Nodal involvement & & & 0.093 \\
\hline pNO & $42(76.4)$ & 32 (53.3) & \\
\hline pN1a & $5(9.1)$ & $9(15.0)$ & \\
\hline $\mathrm{pN} 1 \mathrm{~b}$ & $3(5.5)$ & $7(11.7)$ & \\
\hline pN1c & $1(1.8)$ & $5(8.3)$ & \\
\hline pN2a & $1(1.8)$ & $5(8.3)$ & \\
\hline $\mathrm{pN} 2 \mathrm{~b}$ & $3(5.5)$ & $2(3.3)$ & \\
\hline Presence of metastasis & & & 0.275 \\
\hline M0 & $50(90.9)$ & $58(96.7)$ & \\
\hline M1a & $3(5.5)$ & $2(3.3)$ & \\
\hline M1b & $2(3.6)$ & $0(0)$ & \\
\hline Tumor clearance (UICC-R) ${ }^{\mathrm{a}}$ & & & 0.102 \\
\hline Ro & 50 (90.9) & 59 (98.3) & \\
\hline $\mathrm{R} 1$ & $0(0)$ & $0(0)$ & \\
\hline $\mathrm{R} 2$ & $5(9.1)$ & $1(1.7)$ & \\
\hline AJCC/UICC TNM stage & & & $<0.001$ \\
\hline 0 & $16(29.1)$ & $0(0)$ & \\
\hline I & 21 (38.2) & $15(25.0)$ & \\
\hline$\|$ & $5(9.1)$ & $17(28.3)$ & \\
\hline III & $8(14.5)$ & $26(43.3)$ & \\
\hline IV & $5(9.1)$ & $2(3.3)$ & \\
\hline
\end{tabular}

Values are presented as mean \pm standard deviation or number $(\%)$.

CME, complete mesocolic excision; UICC, the Union for International Cancer Control; AJCC, the American Joint Committee on Cancer.

${ }^{a} \mathrm{R} 0$, no residual tumor; R1, microscopic residual tumor; R2, macroscopic residual tumor. group compared to the standard group $(33.3 \pm 8.1 \mathrm{~cm}$ vs. $27.3 \pm 9.5$ $\mathrm{cm}, \mathrm{P}=0.001)$. Proximal and distal margin clearance from the tumor were longer in the CME group (proximal margin: $15.8 \pm 9.2$ $\mathrm{cm}$ vs. $11.3 \pm 6.8 \mathrm{~cm}, \mathrm{P}=0.018$; distal margin: $14.0 \pm 6.7 \mathrm{~cm}$ vs. $11.3 \pm 6.8 \mathrm{~cm}, \mathrm{P}=0.037$ ) compared to the standard group.

The number of lymph node harvest was higher in the CME right colectomy group. The number of retrieved lymph nodes was $27.0 \pm 11.3$ (median, 24; range, 11 to 61 ) in the CME group vs. $21.7 \pm 2.9$ (median, 19 ; range, 7 to 58 ) in the standard group $(\mathrm{P}=$ $0.007)$. The percentage of patients with 12 or more analyzed nodes was high in both groups ( $98.3 \%$ vs. $92.7 \%, \mathrm{P}=0.192)$. The rate of patients with nodal metastasis was double in the CME

Table 4. Postoperative outcome and morbidity data by treatment group

\begin{tabular}{|c|c|c|c|}
\hline Variable & $\begin{array}{l}\text { Standard right } \\
\text { hemicolectomy } \\
(n=55)\end{array}$ & $\begin{array}{l}\text { CME right } \\
\text { hemicolec- } \\
\text { tomy }(n=60)\end{array}$ & P-value \\
\hline Postoperative morbidity & $27(49.1)$ & $24(40.0)$ & 0.353 \\
\hline Clavien-Dindo classification & & & 0.842 \\
\hline None & $28(50.9)$ & $36(60.0)$ & \\
\hline I & $11(20.0)$ & $9(15.0)$ & \\
\hline$\|$ & $11(20.0)$ & $9(15.0)$ & \\
\hline Illa & $1(1.8)$ & $2(3.3)$ & \\
\hline $\mathrm{lllb}$ & $3(5.5)$ & $2(3.3)$ & \\
\hline IVa & $1(1.8)$ & $2(3.3)$ & \\
\hline $\mathrm{IVb}$ & $0(0)$ & $0(0)$ & \\
\hline V & $0(0)$ & $0(0)$ & \\
\hline Redo surgery & $4(7.3)$ & $3(5.0)$ & 0.708 \\
\hline Red blood cells transfusion & $7(12.7)$ & $5(8.3)$ & 0.542 \\
\hline Hospital stay (day) & $8.8 \pm 8.7$ & $6.7 \pm 4.5$ & 0.124 \\
\hline Unplanned readmission & $3(5.5)$ & $3(5.0)$ & 1 \\
\hline \multicolumn{4}{|l|}{ Type of complication } \\
\hline Anastomotic leak & $3(5.5)$ & $1(1.7)$ & \\
\hline Mechanical bowel obstruction & $1(1.8)$ & $2(3.3)$ & \\
\hline Prolonged postoperative ileus & $6(10.9)$ & $8(13.3)$ & \\
\hline Gastrointestinal bleeding & $1(1.8)$ & $1(1.7)$ & \\
\hline Abdominal bleeding & $0(0)$ & $1(1.7)$ & \\
\hline Deep surgical site infection & $1(1.8)$ & $0(0)$ & \\
\hline Lymphorrhea & $0(0)$ & $1(1.7)$ & \\
\hline Diarrhea & $0(0)$ & $1(1.7)$ & \\
\hline Superficial surgical site infection & $4(7.3)$ & $1(1.7)$ & \\
\hline Cardiovascular & $7(12.7)$ & $6(10.0)$ & \\
\hline Respiratory & $7(12.7)$ & $2(3.3)$ & \\
\hline Urinary tract & $2(3.6)$ & $4(6.7)$ & \\
\hline Ascites & $1(1.8)$ & $0(0)$ & \\
\hline
\end{tabular}

Values are presented as number (\%) or mean \pm standard deviation. 
group (46.7\% vs. $23.6 \%, \mathrm{P}=0.012$ ).

Short-term results are reported in Table 4 . While there were no deaths during the study period in either group, 1 or more complications occurred in 24 patients (40.0\%) in the CME group and in 27 patients $(49.1 \%)$ in the standard group $(\mathrm{P}=0.353)$. Most complications were classified as Clavien-Dindo grade I and II and no differences were observed between the CME and the standard group in terms of severe (Clavien-Dindo grade $\geq$ III) complications ( $10 \%$ vs. $9.1 \%, \mathrm{P}=0.842)$.

Seven patients $(6.1 \%)$ required reoperation due to anastomotic leak $(n=4)$ or mechanical bowel obstruction $(n=3)$. Among these, 4 patients (7.3\%) had undergone a standard colectomy, and 3 patients $(5.0 \%)$ a CME colectomy $(\mathrm{P}=0.708)$. Unplanned readmission occurred in 3 patients for each group $(\mathrm{P}=1)$.

The hospital stay was comparable between the 2 groups $(\mathrm{P}=$ 0.124 ); it was $8.8 \pm 8.7$ (median, 6; range, 3 to 53 ) days after standard colectomy and $6.7 \pm 4.5$ (median, 5; range, 3 to 29) days after CME colectomy.

\section{DISCUSSION}

The main findings of this study are (1) laparoscopic CME right colectomy can be performed safely with no increase of operative time, blood loss, intraoperative complications, and conversion rate compared to the standard right colectomy; (2) laparoscopic CME yields a significantly higher number of lymph-node harvest; (3) the extension of lymph node dissection does not bear higher morbidity or mortality.

The necessity to perform a CME with central lymph-nodes dissection is a highly debated topic in CC surgery $[8,9,16]$. As previously demonstrated in rectal cancer [17], colectomies performed according to CME principles, have yielded an improvement of both the surgical specimen and long-term outcomes [1822]. Furthermore, a recent multicenter study from Japan on 6,866 patients demonstrated the importance of central node assessment for a better stratification of recurrence risk in stage III CC. In fact, the involvement of central nodes was demonstrated to significantly and independently influence prognosis in stages IIIA, IIIB, and IIIC [23].

CME right colectomy is a complex procedure that presents several technical challenges $[9,24,25]$. While CME colectomy is widely adopted in the Far East, very few centers in Europe and North America have incorporated this procedure in their routine practice. This difference brings us to make some considerations. Far Eastern surgical oncology practice is characterized by the execution of extensive dissections and extended lymphadenectomies. Examples can be found in esophageal, gastric, pancreatic, and hepatobiliary as well as rectal cancer surgeries. These extended procedures find their rationale in the fact that optimal local tumor control does impact the long-term outcome. The excellent results reported by Eastern experiences and reproduced by several Western centers seem to confirm the value of this approach [26-28].
The standardization and the wide adoption of extensive resections is probably due to the combination of strict guidelines published by the Japanese Cancer Societies and also favorable clinical characteristics of Eastern patients. In the Western practice, where tumor biology is thought to be the main driver of the outcome and patients more frequently present at older ages with multiple comorbidities (cardiovascular diseases, diabetes, metabolic syndrome, obesity, and previous surgeries) and higher BMIs, extensive resections are less frequently justified.

Looking at the long-term results following CME with CVL/ D3 lymphadenectomy in Far Eastern $[23,29,30]$ and Western experiences $[18,20,21]$, a potential survival benefit is conceivable, although not definitively demonstrated.

In a nationwide Danish study, Bertelsen et al. [21] demonstrated that standardization of the CME surgical technique allowed to improve long-term survival in CC in a way similar to how rectal cancer survivals benefited from TME excisions [31, 32]. In our opinion, both local control and tumor biology play a crucial role in affecting the prognosis in surgically treated patients. West et al. [19] clearly demonstrated that poor quality surgery performed without adhering to surgical principles of embryological planes dissection leads to a significantly worse prognosis. In the same paper, the authors also demonstrated that achieving high-quality surgery in right-sided, transverse and flexures CC is more difficult compared to left-sided ones [19]. CME allows obtaining an en bloc excision of the entire mesocolon together with the lymphovascular tissue and lymph nodes that may contain tumor microfoci $[33,34]$. In this regard, a prospective multicenter study by Protic et al. [35] demonstrated that ultra-staging with immunohistochemistry (IHC) can detect an additional 20\% of cancer deposits in lymph nodes formerly classified as pN0. Interestingly, only $2.6 \%$ of patients with negative nodes on histopathological examination and IHC developed recurrence showing a 5-year disease-free survival of $97 \%$ [35]. One could argue that patients with tumor microfoci in lymph nodes and mesocolon are those that would benefit the most from this extent of surgery.

Given the presumed benefit of CME colectomy, the question of whether such a procedure can be standardized and safely performed in Western countries in a minimally invasive fashion remains to be addressed $[4,10,13,36]$.

The Japan Clinical Oncology Group Study JCOG 0404, a phase 3 randomized controlled study enrolling 1,057 patients demonstrated that laparoscopic CME plus D3 lymphadenectomy (529 patients) was not inferior to the open approach (528 patients) in terms of morbidity and mortality as well as long-term survival [5, 37]. Comparable data have been reported in a retrospective analysis on 1,400 patients. After propensity score analysis, Shida et al. [38] analyzed 365 laparoscopic and 365 open cases. They concluded that laparoscopic CME with D3 dissection is a safe and practical option in selected stage II and III CCs and that some caution should be exercised for patients with high BMI, clinical T4 or N2 disease, and in patients with more than 6-cm tumor di- 
ameter.

Unfortunately, the penetrance of the laparoscopic approach for CRC in Western countries remains significantly lower compared to Japan and Korea, where the CME is also more frequently employed. A potential tool to overcome some technical challenges of this procedure is the use of the robotic platform. Differently from rectal cancer surgery where robotic surgery has been extensively analyzed, only few studies comparing laparoscopic vs. robotic right colectomy have been published. Those studies $[39,40]$ although were able to prove that robotic CME right hemicolectomy is safe and feasible, have failed to demonstrate an advantage of the robotic over the laparoscopic approach. A recent study by Spinoglio et al. [40], that analyzed 202 Italian patients comparing laparoscopic (101 patients) vs. robotic surgery (101 patients), failed to demonstrate any short-term or long-term benefit with the use of the robotic approach.

Our experience represents one of the largest single-center series published to date on the laparoscopic CME approach for rightsided CC by a Western unit. Notably, patients' characteristics of our study group are comparable to those reported in other Western studies and significantly different from Eastern ones [36, 40, 41]. In our CME group, $45.0 \%$ of patients were older than 75 years of age, $31.7 \%$ had a BMI higher than $28 \mathrm{~kg} / \mathrm{m}^{2}, 50.0 \%$ had 2 or more comorbidities, $30.0 \%$ were ASA PS classification III, and $41.7 \%$ had at least one previous abdominal surgery. Nevertheless, intraoperative and postoperative data demonstrated that CME laparoscopic CME right colectomy is feasible, safe, and comparable to standard right colectomy.

In our series, a low percentage of circumferential margins involvement has been found. Also, we observed a significantly improved quality of surgical specimen in terms of lymph node count, length of proximal and distal resection margins. These data resemble previous studies both from Western and Far Eastern experiences $[4,20,22,37,39-41]$ and support the adoption of this technique.

This study suffers some limitations mainly related to its retrospective design and the small sample size. However, the prospective data collection provided us with high quality and accurate data at the time of the analysis. The fact that CME colectomy cases were carried out by a single surgeon, while 2 more surgeons operated on standard colectomy cases may represent another limitation. This should justify the lower rate of intracorporeal anastomoses and conversions to open surgery observed in standard colectomy group. Anyhow, all operating surgeons are senior colorectal surgeons with experience in laparoscopic resection; consequently, the overall quality of surgery can be considered comparable. Another limitation is that the 2 study groups (standard and CME colectomy) are not matched by tumor stage, whereby the standard group counts less malignant patients compared to the CME group. In any case, the stage of presentation unlikely would have altered the results and conclusion of the study. This is because standard colectomy was carried out in an identical manner both in patients with proven malignancy and adenomas. This attitude is justified by the purpose of guarantee the best chance of cure to patients with misdiagnosed carcinoma in the context of large adenomas. Results, such as number of lymph nodes retrieved or the length of the specimen, unlikely would have been different with a better group match. Even in absence of a formal match, the clinical characteristics of the 2 groups were overall similar. This confers value to the analysis of morbidity and other postoperative short-term results. The last limitation is the lack of information about the length and integrity of the mesocolon, and the quality of mesocolic dissection. This is an important point, as its integrity on the pathology specimen reflects the quality of the dissection along the inter-fascial plane as recently proposed by Benz et al. [42] and already demonstrated for TME in rectal cancer. This factor has not been adequately evaluated in most studies and we advocate greater attention on this crucial point in future studies.

In conclusion, laparoscopic CME right colectomy is feasible and safe even in Western series where patients have less favorable clinical characteristics. Laparoscopic CME right colectomy allows obtaining better quality surgical specimens compared to laparoscopic standard colectomy. It is our opinion that the postoperative outcomes and the histopathologic features of the specimens support wider implementation of this procedure. Our experience demonstrated that, in adequately trained centers, the use of laparoscopic CME right colectomy does not increase the risk of postoperative complications.

\section{CONFLICT OF INTEREST}

No potential conflict of interest relevant to this article was reported.

\section{REFERENCES}

1. Kuhry E, Schwenk WF, Gaupset R, Romild U, Bonjer HJ. Longterm results of laparoscopic colorectal cancer resection. Cochrane Database Syst Rev 2008;2008:CD003432.

2. Martel G, Crawford A, Barkun JS, Boushey RP, Ramsay CR, Fergusson DA. Expert opinion on laparoscopic surgery for colorectal cancer parallels evidence from a cumulative meta-analysis of randomized controlled trials. PLoS One 2012;7:e35292.

3. Hohenberger W, Weber K, Matzel K, Papadopoulos T, Merkel S. Standardized surgery for colonic cancer: complete mesocolic excision and central ligation. Technical notes and outcome. Colorectal Dis 2009;11:354-64.

4. West NP, Kobayashi H, Takahashi K, Perrakis A, Weber K, Hohenberger $\mathrm{W}$, et al. Understanding optimal colonic cancer surgery: comparison of Japanese D3 resection and European complete mesocolic excision with central vascular ligation. J Clin Oncol 2012;30:1763-9.

5. Yamamoto S, Inomata M, Katayama H, Mizusawa J, Etoh T, Koni- 
shi F, et al. Short-term surgical outcomes from a randomized controlled trial to evaluate laparoscopic and open D3 dissection for stage II/III colon cancer: Japan Clinical Oncology Group Study JCOG 0404. Ann Surg 2014;260:23-30.

6. Pedrazzani C, Lauka L, Sforza S, Ruzzenente A, Nifosì F, Delaini G, et al. Management of nodal disease from colon cancer in the laparoscopic era. Int J Colorectal Dis 2015;30:303-14.

7. West NP, Sutton KM, Ingeholm P, Hagemann-Madsen RH, Hohenberger W, Quirke P. Improving the quality of colon cancer surgery through a surgical education program. Dis Colon Rectum 2010;53:1594-603.

8. Gouvas N, Agalianos C, Papaparaskeva K, Perrakis A, Hohenberger W, Xynos E. Surgery along the embryological planes for colon cancer: a systematic review of complete mesocolic excision. Int J Colorectal Dis 2016;31:1577-94.

9. Athanasiou CD, Markides GA, Kotb A, Jia X, Gonsalves S, Miskovic D. Open compared with laparoscopic complete mesocolic excision with central lymphadenectomy for colon cancer: a systematic review and meta-analysis. Colorectal Dis 2016;18:O224-35.

10. Emmanuel A, Haji A. Complete mesocolic excision and extended (D3) lymphadenectomy for colonic cancer: is it worth that extra effort? A review of the literature. Int J Colorectal Dis 2016;31:797804.

11. Alsabilah J, Kim WR, Kim NK. Vascular structures of the right colon: incidence and variations with their clinical implications. Scand J Surg 2017;106:107-15.

12. Tajima Y, Ishida H, Ohsawa T, Kumamoto K, Ishibashi K, Haga N, et al. Three-dimensional vascular anatomy relevant to oncologic resection of right colon cancer. Int Surg 2011;96:300-4.

13. Gouvas N, Pechlivanides G, Zervakis N, Kafousi M, Xynos E. Complete mesocolic excision in colon cancer surgery: a comparison between open and laparoscopic approach. Colorectal Dis 2012; 14:1357-64.

14. Pedrazzani C, Lazzarini E, Turri G, Fernandes E, Conti C, Tombolan $\mathrm{V}$, et al. Laparoscopic complete mesocolic excision for rightsided colon cancer: analysis of feasibility and safety from a single Western center. J Gastrointest Surg 2019;23:402-7.

15. Dindo D, Demartines N, Clavien PA. Classification of surgical complications: a new proposal with evaluation in a cohort of 6336 patients and results of a survey. Ann Surg 2004;240:205-13.

16. Kim NK, Kim YW, Han YD, Cho MS, Hur H, Min BS, et al. Complete mesocolic excision and central vascular ligation for colon cancer: principle, anatomy, surgical technique, and outcomes. Surg Oncol 2016;25:252-62.

17. Heald RJ. The 'Holy Plane' of rectal surgery. J R Soc Med 1988; 81:503-8.

18. Benitez Majano S, Di Girolamo C, Rachet B, Maringe C, Guren MG, Glimelius B, et al. Surgical treatment and survival from colorectal cancer in Denmark, England, Norway, and Sweden: a population-based study. Lancet Oncol 2019;20:74-87.

19. West NP, Morris EJ, Rotimi O, Cairns A, Finan PJ, Quirke P. Pathology grading of colon cancer surgical resection and its associa- tion with survival: a retrospective observational study. Lancet Oncol 2008;9:857-65.

20. Merkel S, Weber K, Matzel KE, Agaimy A, Göhl J, Hohenberger W. Prognosis of patients with colonic carcinoma before, during and after implementation of complete mesocolic excision. Br J Surg 2016;103:1220-9.

21. Bertelsen CA, Neuenschwander AU, Jansen JE, Wilhelmsen M, Kirkegaard-Klitbo A, Tenma JR, et al. Disease-free survival after complete mesocolic excision compared with conventional colon cancer surgery: a retrospective, population-based study. Lancet Oncol 2015;16:161-8.

22. Cho MS, Baek SJ, Hur H, Soh Min B, Baik SH, Kim NK. Modified complete mesocolic excision with central vascular ligation for the treatment of right-sided colon cancer: long-term outcomes and prognostic factors. Ann Surg 2015;261:708-15.

23. Shinto E, Hida JI, Kobayashi H, Hashiguchi Y, Hase K, Ueno H, et al. Prominent information of jN3 positive in stage III colorectal cancer removed by D3 dissection: retrospective analysis of 6866 patients from a multi-institutional database in Japan. Dis Colon Rectum 2018;61:447-53.

24. Bertelsen CA, Neuenschwander AU, Jansen JE, Kirkegaard-Klitbo A, Tenma JR, Wilhelmsen M, et al. Short-term outcomes after complete mesocolic excision compared with 'conventional' colonic cancer surgery. Br J Surg 2016;103:581-9.

25. Bae SU, Yang SY, Min BS. Totally robotic modified complete mesocolic excision and central vascular ligation for right-sided colon cancer: technical feasibility and mid-term oncologic outcomes. Int J Colorectal Dis 2019;34:471-9.

26. Roviello F, Pedrazzani C, Marrelli D, Di Leo A, Caruso S, Giacopuzzi S, et al. Super-extended (D3) lymphadenectomy in advanced gastric cancer. Eur J Surg Oncol 2010;36:439-46.

27. Bagante F, Tran T, Spolverato G, Ruzzenente A, Buttner S, Ethun CG, et al. Perihilar cholangiocarcinoma: number of nodes examined and optimal lymph node prognostic scheme. J Am Coll Surg 2016;222:750-9.

28. Kim HJ, Choi GS, Park JS, Park SY, Cho SH, Lee SJ, et al. Optimal treatment strategies for clinically suspicious lateral pelvic lymph node metastasis in rectal cancer. Oncotarget 2017;8:100724-33.

29. Kotake K, Mizuguchi T, Moritani K, Wada O, Ozawa H, Oki I, et al. Impact of D3 lymph node dissection on survival for patients with T3 and T4 colon cancer. Int J Colorectal Dis 2014;29:847-52.

30. Shimada Y, Hamaguchi T, Mizusawa J, Saito N, Kanemitsu Y, Takiguchi N, et al. Randomised phase III trial of adjuvant chemotherapy with oral uracil and tegafur plus leucovorin versus intravenous fluorouracil and levofolinate in patients with stage III colorectal cancer who have undergone Japanese $\mathrm{D} 2 / \mathrm{D} 3$ lymph node dissection: final results of JCOG0205. Eur J Cancer 2014;50:2231-40.

31. Martling AL, Holm T, Rutqvist LE, Moran BJ, Heald RJ, Cedemark B. Effect of a surgical training programme on outcome of rectal cancer in the County of Stockholm. Lancet 2000;356:93-6.

32. Dutch Snapshot Research Group. Benchmarking recent national practice in rectal cancer treatment with landmark randomized 
controlled trials. Colorectal Dis 2017;19:O219-31.

33. Ueno H, Mochizuki H, Akagi Y, Kusumi T, Yamada K, Ikegami M, et al. Optimal colorectal cancer staging criteria in TNM classification. J Clin Oncol 2012;30:1519-26.

34. Nagayoshi K, Ueki T, Nishioka Y, Manabe T, Mizuuchi Y, Hirahashi $\mathrm{M}$, et al. Tumor deposit is a poor prognostic indicator for patients who have stage II and III colorectal cancer with fewer than 4 lymph node metastases but not for those with 4 or more. Dis Colon Rectum 2014;57:467-74.

35. Protic M, Stojadinovic A, Nissan A, Wainberg Z, Steele SR, Chen DC, et al. Prognostic effect of ultra-staging node-negative colon cancer without adjuvant chemotherapy: a prospective National Cancer Institute-sponsored clinical trial. J Am Coll Surg 2015; 221:643-51.

36. Melich G, Jeong DH, Hur H, Baik SH, Faria J, Kim NK, et al. Laparoscopic right hemicolectomy with complete mesocolic excision provides acceptable perioperative outcomes but is lengthy: analysis of learning curves for a novice minimally invasive surgeon. Can J Surg 2014;57:331-6.

37. Kitano S, Inomata M, Mizusawa J, Katayama H, Watanabe M, Yamamoto S, et al. Survival outcomes following laparoscopic versus open D3 dissection for stage II or III colon cancer (JCOG0404): a phase 3, randomised controlled trial. Lancet Gastroenterol Hepatol 2017;2:261-8.

38. Shida D, Ochiai H, Tsukamoto S, Kanemitsu Y. Long-term outcomes of laparoscopic versus open D3 dissection for stage II/III colon cancer: results of propensity score analyses. Eur J Surg Oncol 2018;44:1025-30.

39. Park JS, Choi GS, Park SY, Kim HJ, Ryuk JP. Randomized clinical trial of robot-assisted versus standard laparoscopic right colectomy. Br J Surg 2012;99:1219-26.

40. Spinoglio G, Bianchi PP, Marano A, Priora F, Lenti LM, Ravazzoni F, et al. Robotic versus laparoscopic right colectomy with complete mesocolic excision for the treatment of colon cancer: perioperative outcomes and 5-year survival in a consecutive series of 202 patients. Ann Surg Oncol 2018;25:3580-6.

41. Adamina M, Manwaring ML, Park KJ, Delaney CP. Laparoscopic complete mesocolic excision for right colon cancer. Surg Endosc 2012;26:2976-80.

42. Benz S, Tannapfel A, Tam Y, Grünenwald A, Vollmer S, Stricker I. Proposal of a new classification system for complete mesocolic excison in right-sided colon cancer. Tech Coloproctol 2019;23: 251-7. 